TAO, Vol. 16, No. 5, 1177-1188, December 2005

\title{
Daily Variation and Effect on Inland Air Quality of the Strong NOx Emissions from Ships in the Osaka Bay, Japan
}

\author{
Yasuyuki Itano ${ }^{1, *}$, Hiroshi Bandow ${ }^{2}$, Norimichi Takenaka ${ }^{2}$, Atsushi Asayama ${ }^{3}$, Hiroyuki Tanaka ${ }^{4}$, \\ Shinji Wakamatsu ${ }^{5}$ And Kentaro Murano ${ }^{5}$
}

(Manuscript received 27 January 2005, in final form 21 July 2005)

\begin{abstract}
Investigations of air pollutants were conducted aboard a research vessel anchoring for several hours at several sites while cruising over Osaka Bay and the surrounding sea area in Japan. The concentrations of nitrogen oxides (NOx) within Osaka Bay sometimes exceeded 60 ppb (parts per billion by volume) and showed a clear diurnal variation pattern with a broad peak in the daytime. A similarity was observed between the variation patterns of NOx concentration and sea traffic on the bay. Outside the bay, NOx concentration was constant at about $13 \mathrm{ppb}$. Atmospheric monitoring from the rooftop of a skyscraper on the coast often showed high levels of NOx in air masses from Osaka Bay, seemingly affected by ship emissions. On the other hand, low NOx concentrations $(<5 \mathrm{ppb})$, which never appeared in the air masses from the urban area, were also often observed. The effects of NOx emissions from ships on inland air quality thus seem to vary widely depending on the density of sea traffic on the bay.
\end{abstract}

(Key words: Nitrogen oxides, Ship emissions, Temporal variation)

${ }^{1}$ Osaka City Institute of Public Health and Environmental Sciences, 8-34 Tojo-cho, Tennoji-ku, Osaka, Japan

${ }^{2}$ Graduate School of Osaka Prefecture University, 1-1 Gakuen-cho, Sakai, Osaka, Japan

${ }^{3}$ National Research Institute of Fisheries and Environment of Inland Sea, 2-17-5 Marunishi, Ohno-cho, Hiroshima, Japan

${ }^{4}$ Bureau of Environmental Information, Osaka City Government, 3-20 Nakanoshima, Kita-ku, Osaka, Japan

${ }^{5}$ National Institute for Environmental Studies, 16-2 Onogawa, Tsukuba, Ibaraki 305-8506, Japan

* Corresponding author address: Dr. Yasuyuki Itano, Osaka City Institute of Public Health and Environmental Sciences, Tojo-cho, Tennoji-ku, Osaka, Japan; E-mail: yasuyuki.itano@iphes.city.osaka.jp 


\section{INTRODUCTION}

Atmospheric oxides of nitrogen have been recognized as principal pollutants since the early history of industrialized countries (Seinfeld 1975). Because of the well-known adverse effects of nitrogen dioxide $\left(\mathrm{NO}_{2}\right)$ on human health (Lee 1980), air quality standards have been set in many countries. Because nitric oxide (NO), which is formed during the combustion processes, oxidizes to form $\mathrm{NO}_{2}$, emissions of $\mathrm{NOx}\left(\mathrm{NO}+\mathrm{NO}_{2}\right)$ from motor vehicles and factories have been controlled. However, levels of NOx in many large cities still seem to remain high (Baldasano et al. 2003). In the Osaka-Kobe metropolitan area in Japan, NOx concentrations in the air have not been effectively controlled though emissions from motor vehicles and stationary sources have declined significantly due to severe regulations placed on these sources (Bureau of Agriculture, Forestry and Fisheries of Osaka Prefecture 2001). The national air quality standard for $\mathrm{NO}_{2}$, less than $60 \mathrm{ppb}$ (parts per billion by volume) as an hourly average, has not been met at most sites in the area.

Recently, attention has been paid to emissions from ships as an unregulated source of NOx (Cooper and Andreasson 1999; Isakson et al. 2001; Cooper 2001, 2003; Corbett 2002; Saxe and Larsen 2004). Because many large cities face the sea and thus have ports, ship emissions would affect the air quality of these coastal sites (Isakson et al. 2001; Saxe and Larsen 2004). The Osaka-Kobe metropolitan area faces Osaka Bay, which is dotted with more than 40 commercial and fishing ports, including 3 identified important ports, designated by law as important to the national economy (Fig. 1). Because of the heavy sea traffic, the emission of NOx from ships over the bay in 1994 was estimated to be as large as $22340 \mathrm{t} \mathrm{y}^{-1}$, comparable to the $28220 \mathrm{t} \mathrm{y}^{-1}$ estimated from other mobile sources over the entire area of Osaka Prefecture (Nishikawa and Nagano 1998). Simulation studies show a significant contribution of ship emissions to the atmospheric NOx over inland sites (Kondo et al. 1999; Ohara et al. 2001). Therefore, it is important to study the actual situation of pollution over sea areas as well as inland areas; however, investigations of atmospheric pollution in marine areas seem sparse (Nishikawa et al. 1997). Moreover, to our knowledge, there is no information on the temporal variation of atmospheric pollutants over marine areas. In this study, we conducted duplicate investigations of marine air pollutants over Osaka Bay and the surrounding sea area aboard a research vessel. During the cruise, the vessel anchored at several sites within the area for about $10 \mathrm{~h}$ each. From the results of this investigation, we discuss features of the temporal variation and spatial distribution of air pollutants, especially NOx. In addition to the on-board investigations, we conducted atmospheric monitoring from the rooftop of a 250-m-high skyscraper standing on the coast of Osaka Bay. Using this dataset, we present a preliminary study on the effect of ship emissions on the quality of inland air.

\section{OBSERVATION}

\subsection{Marine Air Investigation}

The research vessel (R/V) Shirafuji-maru (138t), belonging to the National Research Institute of Fisheries and Environment of Inland Sea, Japan, was employed for the marine atmo- 


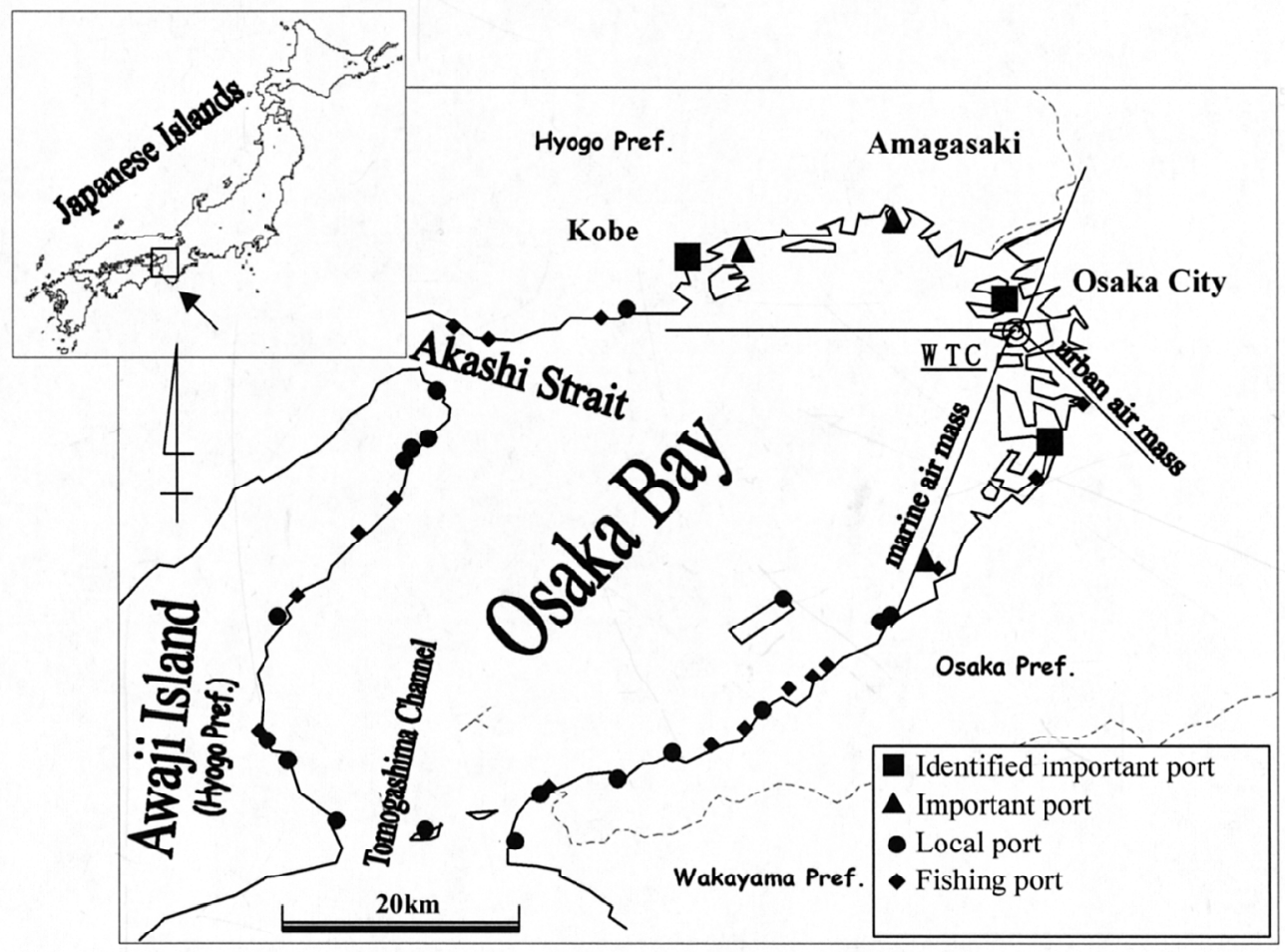

Fig. 1. The Osaka-Kobe Metropolitan Area and distribution of ports around Osaka Bay, Japan. The location of the WTC building and classification of air masses are also shown (see text).

spheric investigation. We carried out two investigations, from 26 to 30 October 2001 and from 13 to 21 May 2002. R/V Shirafuji-maru left Osaka Port to cruise from Osaka Bay to the Pacific Ocean through the Tomogashima and Kii Channels, anchoring for 7 to $23 \mathrm{~h}$ at several sites along the courses shown in Fig. 2. Table 1 shows the timetable for both cruises.

Atmospheric $\mathrm{NO}$ and $\mathrm{NO}_{2}$ were monitored with a chemiluminescence-based instrument (NA621, Kimoto Electric, Co. Ltd., Osaka, Japan); $\mathrm{O}_{3}$ was monitored with a UV absorptionbased instrument (Model 1006 AHJ, Dasibi Environmental Co. Ltd., California, USA) in the laboratory of R/V Shirafuji-maru. One-minute-averaged data for $\mathrm{NO}, \mathrm{NO}_{2}$, and $\mathrm{O}_{3}$ were logged on a PC. Unfortunately, because of an electrical problem, $\mathrm{O}_{3}$ data is missing for 2002. The air intake was set on a flagpole about $3 \mathrm{~m}$ above the front deck ( $7 \mathrm{~m}$ from the sea surface). The stack of R/V Shirafuji-maru, was also about $3 \mathrm{~m}$ high but located on the rear deck some $15 \mathrm{~m}$ behind the intake. The stack plume could not affect monitoring unless strong winds blew from the stern. The air sample flowed through a Teflon tube ( $4 \mathrm{~mm}$ i.d. $\times 15 \mathrm{~m} \mathrm{long}$ ) to a $100 \mathrm{~cm}^{3}$ glass manifold connected to the two instruments. The flow rates were $300 \mathrm{~cm}^{3} \mathrm{~min}^{-1}$ for NOx measurements and $2000 \mathrm{~cm}^{3} \mathrm{~min}^{-1}$ for the $\mathrm{O}_{3}$ measurements, resulting in a mean residence time for the air sample in the tubing of about $6 \mathrm{~s}$. This time seems large enough to affect 


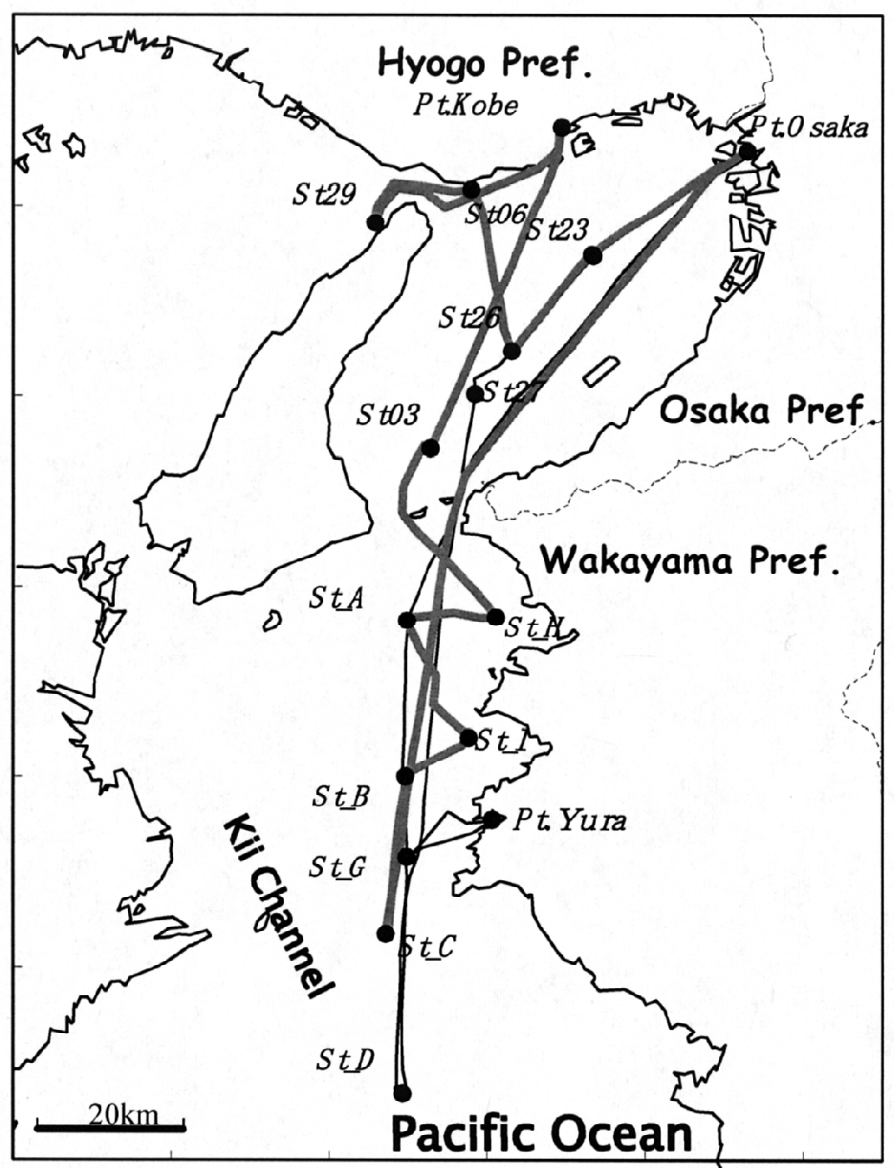

Fig. 2. Routes of R/V Shirafuji-maru in 2001 (thin line) and 2002 (thick gray line). Anchoring sites are indicated by closed circles. Refer to Table 2 for description of sites.

pollutant measurement owing to the fast reaction of $\mathrm{NO}$ with $\mathrm{O}_{3}$ (Atkinson et al. 1989). Therefore, in the following results and discussion we evaluated the value of $\mathrm{NOx}\left(\mathrm{NO}+\mathrm{NO}_{2}\right)$ and oxidant $\left(\mathrm{Ox}: \mathrm{O}_{3}+\mathrm{NO}_{2}\right)$, both of which would be conserved regardless of the reaction (Kley et al. 1999).

Two auxiliary engines remained working during anchoring, besides which, a number of ships passed nearby during these times. Therefore, monitoring data could have been directly affected by their emissions. To eliminate such data, we statistically filtered the data. Because the levels of primary pollutants from sources immediately nearby tend to show a large variance, we excluded certain data so that the relative standard deviation over $10 \mathrm{~min}$ for NO would not exceed 50\%. Unless otherwise mentioned, we investigated the hourly averaged concentration data for pollutants after this filtering. 
Table 1. Summary of investigation cruises in 2001 and 2002.

\begin{tabular}{cccc}
\hline \multicolumn{1}{c}{ Sites } & arrival & & leave \\
\hline Oct. 2001 & & & \\
Pt.Osaka & - & & $2609: 50$ \\
St23 & $2610: 40$ & - & $2623: 30$ \\
St27 & $2700: 40$ & - & $2713: 20$ \\
St_A & $2715: 00$ & - & $2803: 50$ \\
St_G & $2805: 10$ & - & $2812: 40$ \\
Pt_Yura & $2813: 30$ & - & $2909: 10$ \\
St_G & $2909: 50$ & - & $2917: 50$ \\
St_D & $2919: 30$ & - & $3008: 00$ \\
Pt.Osaka & $3015: 00$ & & - \\
May 2002 & & & \\
Pt.Osaka & - & & $1313: 10$ \\
St23 & $1314: 10$ & - & $1408: 00$ \\
St26 & $1408: 50$ & - & $1417: 00$ \\
St06 & $1418: 10$ & - & $1508: 00$ \\
St29 & $1508: 50$ & - & $1608: 00$ \\
Pt.Kobe & $1610: 50$ & - & $1708: 30$ \\
St03 & $1710: 50$ & - & $1719: 00$ \\
St_H & $1720: 30$ & - & $1808: 30$ \\
St_A & $1809: 10$ & - & $1817: 00$ \\
St_I & $1818: 00$ & - & $1908: 30$ \\
St_B & $1909: 20$ & - & $1916: 50$ \\
St_C & $1918: 10$ & - & $2008: 30$ \\
Pt.Osaka & $2014: 10$ & - & $2112: 00$ \\
\hline & & &
\end{tabular}

* Refer to Fig. 2 for description of sites.

\subsection{Monitoring at Coastal Sites}

To compare the levels of pollutants in the marine atmosphere with those inland, we examined monitoring data at several coastal sites. Such data were provided by routine monitoring programs conducted by local governments. All the data considered in this study were from general air monitoring stations, where the effects of mobile sources are generally small. In addition to this data, we conducted observations at the rooftop of a skyscraper, the World Trade Center (WTC) building, from 1 to 30 May 2002. Monitored components were NO, $\mathrm{NO}_{2}$ (NA623, Kimoto), and $\mathrm{O}_{3}$ (Model 1150, Dylec). Their 10-min-averaged values were logged on a PC, and hourly averaged concentrations are shown in this paper. Meteorological factors were provided by World Trade Center Building (Osaka), Inc. The WTC building stands on the coast facing southwest onto Osaka Bay. Osaka City, the capital of the Osaka-Kobe 
metropolitan area extends to the east of the WTC building. At $240 \mathrm{~m}$ above the ground, the observations seemed high enough to eliminate direct influences from neighboring sources on the ground. Data associated with southwesterly winds (WSW, SW, and SSW) were thus regarded as marine air masses from the bay, while data associated with easterly winds (NNE, NE, ENE, E, ESE, and SE) were regarded as urban air masses from the city (Fig. 1).

\section{RESULTS AND DISCUSSION}

\subsection{Pollution of the Marine Atmosphere}

High levels of NOx were observed during the two periods of observation aboard R/V Shirafuji-maru; NOx exceeded $60 \mathrm{ppb}$ for 27 of the 296 total monitoring hours (Fig. 3). The average concentrations of NOx and Ox at each anchorage site are summarized in Table 2. As a whole, higher NOx concentrations were observed inside the bay than outside, though rela-
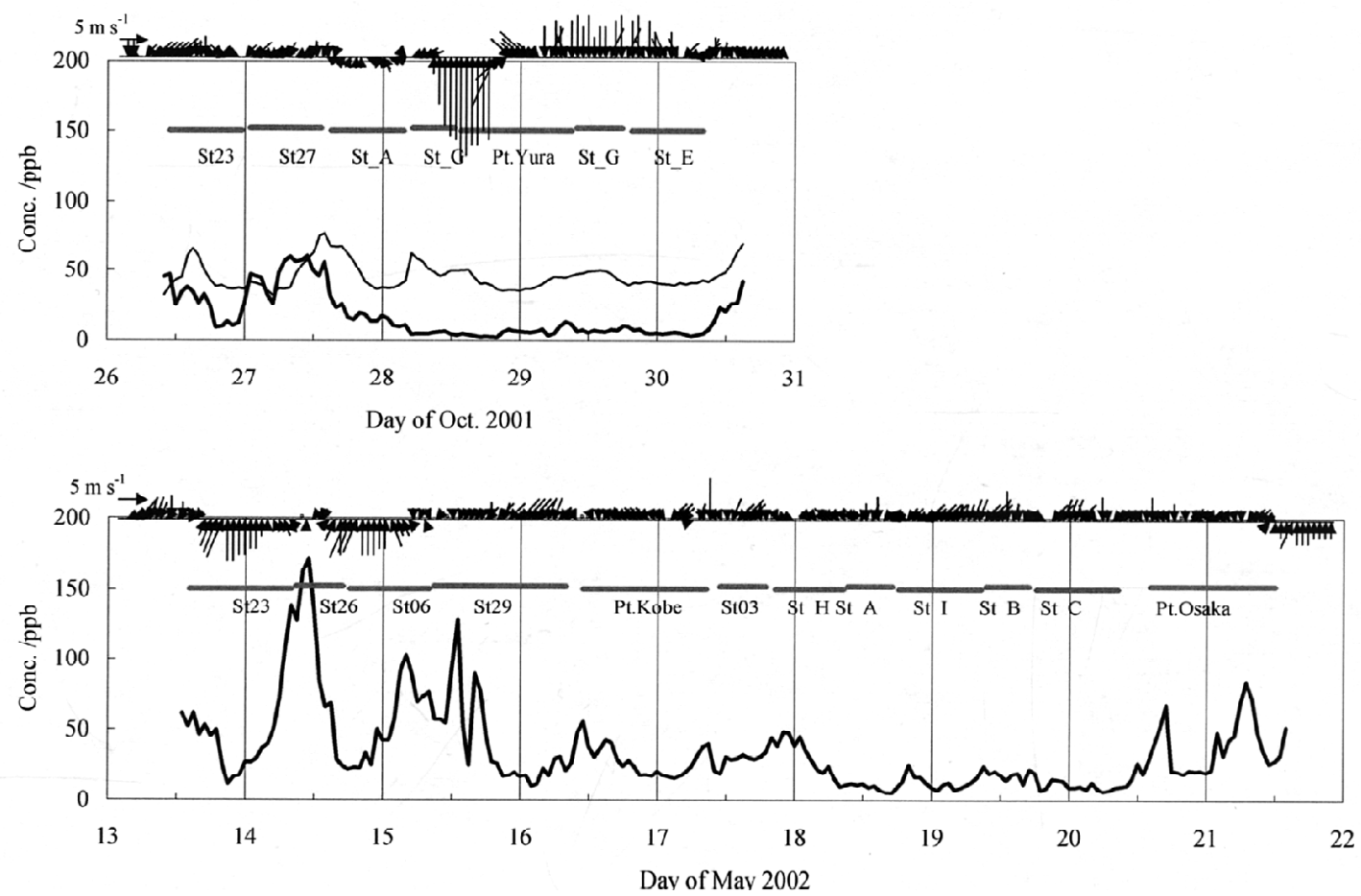

Fig. 3. Variation in NOx (thick line) and Ox (thin line) with time during the investigation cruises in 2001 (top) and 2002 (bottom). Anchoring sites and periods are also indicated with grey horizontal bars. Wind vectors show the wind at Tomogashima Meteorological Observatory. Ox data are missing for 2002 (see text). 
Table 2. Average concentration of air pollutants at each anchoring site*.

\begin{tabular}{|c|c|c|c|c|c|c|}
\hline \multirow[b]{2}{*}{ Sites } & \multirow[b]{2}{*}{$\mathrm{n}$} & \multicolumn{2}{|c|}{$\mathrm{NOx} / \mathrm{ppb}$} & \multicolumn{2}{|c|}{$\mathrm{Ox} / \mathrm{ppb}$} & \multirow[b]{2}{*}{ Description } \\
\hline & & ave & sd & ave & $\mathrm{sd}$ & \\
\hline \multicolumn{7}{|l|}{ Oct. 2001} \\
\hline St23 & 77 & 23.7 & 12.2 & 45.7 & 10.2 & central Osaka Bay \\
\hline $\mathrm{St} 27$ & 76 & 48.3 & 12.6 & 45.4 & 12.0 & central Osaka Bay \\
\hline Pt.Yura & 118 & 5.6 & 3.3 & 40.9 & 4.8 & Port Yura, a local port \\
\hline St_A & 77 & 16.9 & 6.1 & 48.6 & 12.4 & Tomogashima Channel \\
\hline St_D & 75 & 5.2 & 1.5 & 41.2 & 1.3 & Pacific Ocean \\
\hline St_G & 93 & 5.8 & 1.3 & 49.5 & 4.4 & Kii Channel \\
\hline \multicolumn{7}{|l|}{ May 2002} \\
\hline Pt.Osaka & 131 & 39.2 & 21.6 & & & Port Osaka, a specified important port \\
\hline Pt.Kobe & 130 & 27.6 & 11.1 & & & Port Kobe, a specified important port \\
\hline St03 & 51 & 29.6 & 4.8 & & & Osaka Bay near Tomogashima Channel \\
\hline St06 & 83 & 55.8 & 27.6 & & & Osaka Bay near Akashi Strait \\
\hline St23 & 107 & 45.2 & 27.9 & & & central Osaka Bay \\
\hline St26 & 49 & 98.3 & 54.0 & & & central Osaka Bay \\
\hline St29 & 139 & 38.9 & 36.0 & & & Sea of Harima near Akashi Strait \\
\hline St_A & 47 & 9.5 & 2.8 & & & Tomogashima Channel \\
\hline St_B & 45 & 17.4 & 4.6 & & & Kii Channel \\
\hline St_C & 86 & 9.9 & 3.2 & & & Pacific Ocean \\
\hline St_H & 72 & 31.1 & 13.7 & & & Kii Channel near Wakaura Bay \\
\hline St_I & 87 & 13.4 & 5.7 & & & Kii Channel \\
\hline
\end{tabular}

* Data based on 10-min-averaged values.

tively high NOx concentrations were observed at a site outside the bay $\left(\mathrm{St} \_\mathrm{H}\right)$. The high NOx concentrations observed at $\mathrm{St} \_\mathrm{H}$ are related to its location near Wakaura Bay, an economically important port with a high density of sea traffic. On 14 May 2002, during drizzly weather conditions the wind had gradually subsided by around noon after which time the concentration of NOx increased to an especially high level (Fig. 3). The NOx level decreased after peaking at about $170 \mathrm{ppb}$ as the wind became stronger. During the high NOx concentration episode, which lasted from 0:00 to 17:00 JST, under stagnant weather conditions, R/V Shirafuji-maru anchored at two sites, St23 and St26. As shown in Fig. 2, the distance between the two sites was about $20 \mathrm{~km}$. Therefore, this episode was not a local phenomenon, but extended for at least a distance of $20 \mathrm{~km}$. The average NOx concentration over the bay during this event was higher than average NOx concentrations at most coastal sites and comparable to that in Osaka City (Fig. 4). These results imply strong NOx emissions within the bay.

Figure 5 shows the averaged diurnal variation of NOx within and outside the bay, in which data for both periods was compiled. NOx concentration outside the bay was almost constant at an average of $12.7 \mathrm{ppb}$, while a clear diurnal pattern of change was observed inside the bay. Although during the nighttime the concentration of NOx inside the bay was similar to that outside the bay, it increased to $>40 \mathrm{ppb}$ during the daytime. Urban sources are unlikely to be responsible for this midday peak because, in general, NOx in urban sites shows a bimodal 


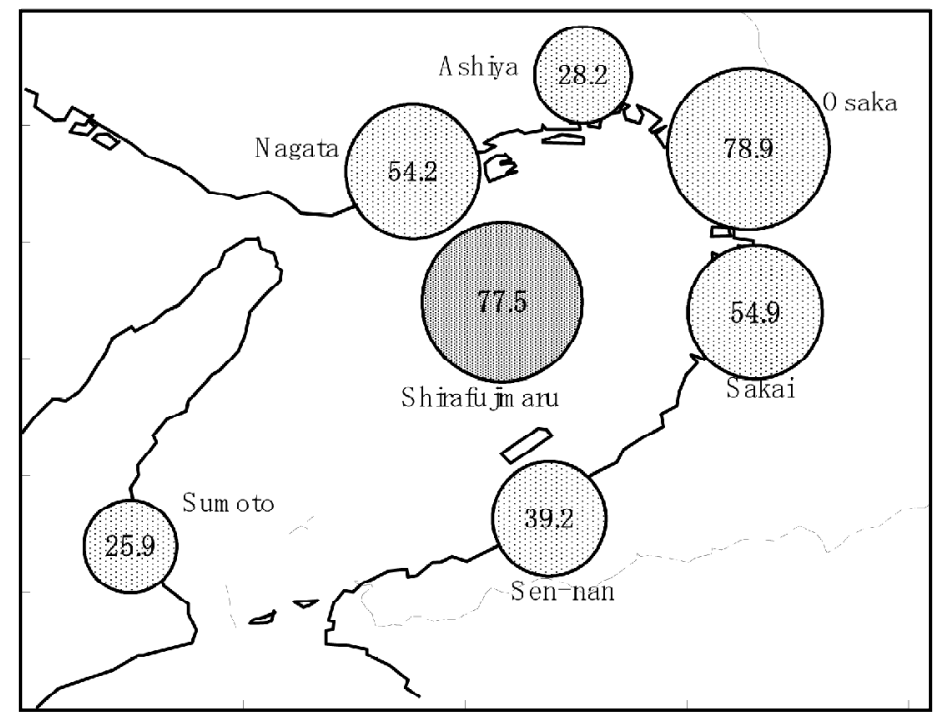

Fig. 4. Comparison of average NOx concentration over Osaka Bay with that at several coastal sites from 0:00 to 17:00 on 14 May 2002. Units in ppb.

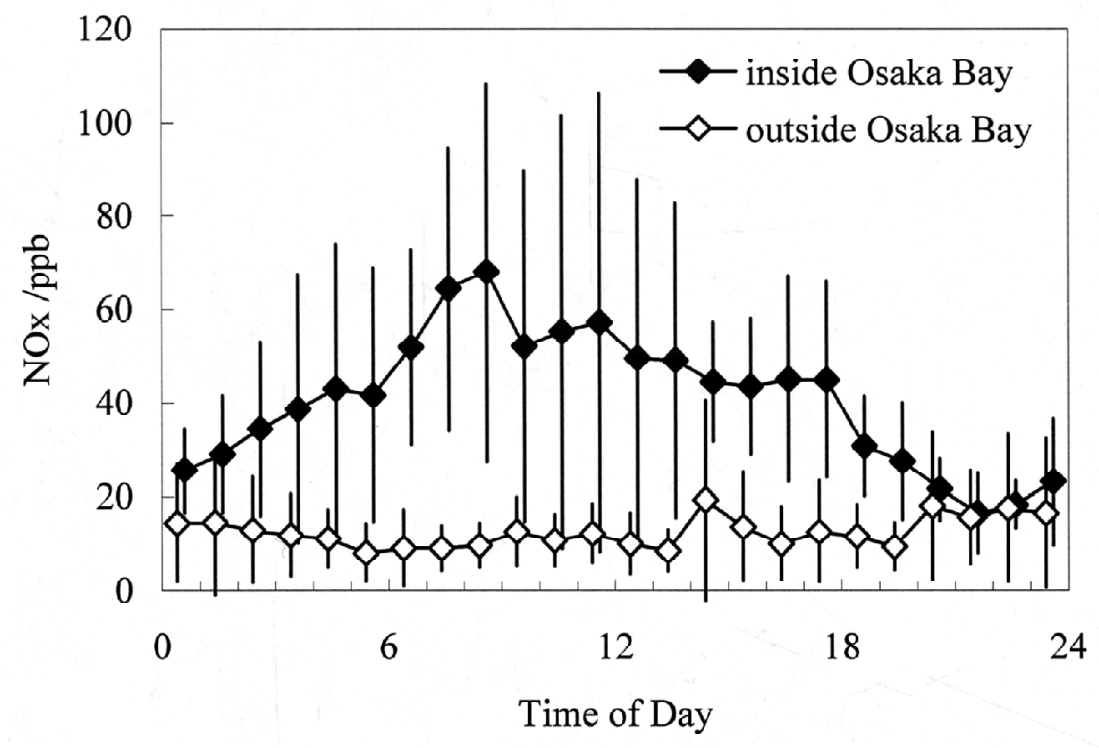

Fig. 5. Averaged diurnal variation in concentration of NOx inside Osaka Bay (filled diamonds) and outside (open diamonds). Data from both the 2001 and 2002 investigations are included. Whiskers represent 1 standard deviation for each data point. 


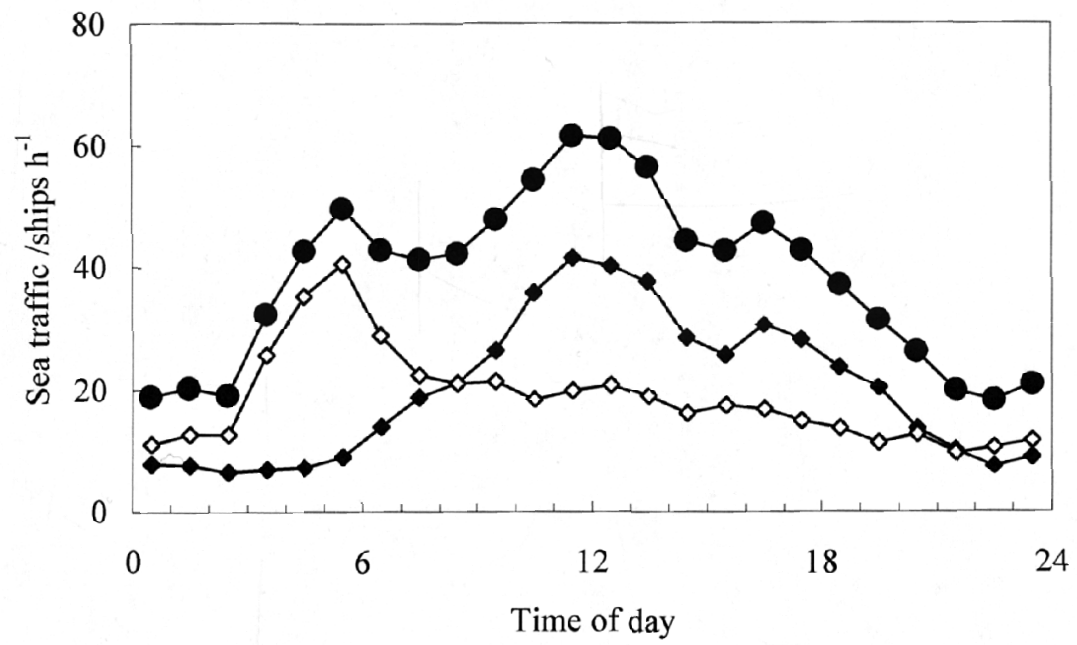

Fig. 6. Diurnal variation pattern of sea traffic in the Akashi Strait. Averaged number of ships entering (filled diamonds), exiting (open diamonds) Osaka Bay and the total (filled circles) and shown. Data adopted from Osakawan Traffic Advisory Service Center, Japan Coast Guard (2001).

diurnal variation, peaking in the morning and evening in relation to vehicle traffic (Shi and Harrison 1997). Figure 6 shows the daily variation of sea traffic monitored in the Akashi Strait. Comparing the variations of NOx concentration within the bay and the traffic, their diurnal pattern shows similar features, i.e., a trimodal broad daytime maximum. These results suggest that the daytime increase in NOx concentration within the bay is related to ship emissions, and that higher ship density within the bay caused the difference in the variation pattern of NOx.

Although the data are limited, this would be the first report showing data for $\mathrm{O}_{3}$ over Osaka Bay. Ox showed a diurnal variation with a daytime maximum on the first two days of the investigation in 2001, when R/V Shirafuji-maru was within the bay (Fig. 3). This diurnal variation might be a result of in situ production of $\mathrm{O}_{3}$ over the bay due to high levels of NOx, a precursor of $\mathrm{O}_{3}$. In this study, $\mathrm{O}_{3}$ data are available only for 2001, as it was stormy when $\mathrm{R} /$ V Shirafuji-maru was outside the bay (see Fig. 3); hence variation patterns of Ox inside and outside the bay were not compared. However, our results imply that the effect of NOx emission from ships could appear not only as NOx but also $\mathrm{O}_{3}$.

\subsection{Impact of Ship Emissions on Inland Air Quality}

To investigate the effects of ship emissions, we examined the relation between NOx concentration and wind velocity for marine air masses from the bay and for urban air masses from the city observed at the WTC building (Fig. 7). For both air masses, higher NOx concentrations were observed at lower wind velocities. This feature is typical in air masses from areas of 

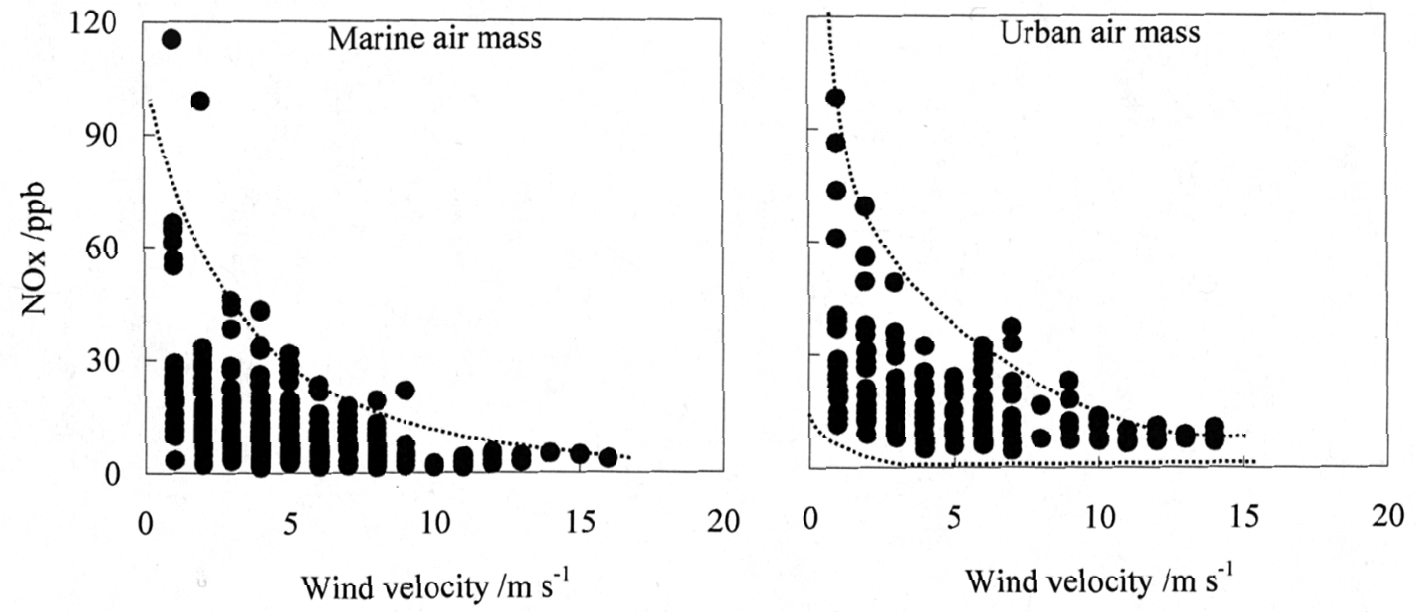

Fig. 7. NOx concentration versus wind velocity for marine air masses from Osaka Bay (left hand side) and urban air masses from Osaka City (right hand side) observed at the WTC building. Dotted lines are for visual aid.

high emission, and thus implies a significant contribution of ship emissions to the inland air quality. However, note that concentrations lower than $5 \mathrm{ppb}$ were frequently observed only in the marine air masses. Thus, the NOx levels in marine air masses are basically low. Regarding the data in detail at low wind velocities, NOx concentration in marine air masses can be below $5 \mathrm{ppb}$ even at very low wind velocity, whereas urban air mass NOx concentrations increased with decreasing wind velocity, reflecting larger and continuous emissions. This suggests that the effects from ships vary from negligible to comparably high with urban emissions, seemingly dependent upon ship density over the bay. Because NOx data from our measurements aboard R/V Shirafuji-maru showed a clear diurnal variation over the bay, we expected that the NOx in marine air masses measured at the WTC would also show a similar pattern of variation. We examined the daytime/nighttime data for marine air masses (data not shown) but the differences were not as distinct, though there was a slight tendency for nighttime data to appear in the low NOx region. We ascribed the reason to the height of the monitoring $(240 \mathrm{~m})$, where vertical motion of NOx could also have an effect on measured concentrations.

\section{CONCLUSIONS}

We investigated the temporal and spatial variation of NOx and Ox in the marine atmosphere over Osaka Bay and the surrounding sea area. High levels of NOx concentration exceeding $60 \mathrm{ppb}$ were sometimes observed inside the bay. The concentration of NOx outside the bay remained constant at about $13 \mathrm{ppb}$. However, a clear diurnal variation was observed inside the bay. The level of NOx varied widely from a nighttime level similar to that outside 
the bay to a daytime level above $40 \mathrm{ppb}$. The NOx variation inside the bay correlated with sea traffic, implying significant emission from ships on the bay. The Ox over Osaka Bay also showed a clear diurnal variation with a daytime maximum similarly to the pattern of Ox concentrations in the urban atmosphere.

The concentrations of NOx in air masses from Osaka Bay were higher at lower wind velocities. This relation was similar to that observed in the urban air masses from Osaka City. Thus ship emission significantly affected inland NOx air quality. However, low NOx concentrations below 5 ppb were frequently observed in air masses from the bay, while such low values never appeared in urban air masses. The contribution of ship emissions over the bay therefore varied widely, seemingly dependent upon sea traffic conditions. This suggests that the pattern of variation in emissions must be taken into consideration when evaluating and predicting the effects of ship emissions on inland air quality.

Acknowledgements We express our appreciation to the crew of R/V Shirafuji-maru for their cooperation in our investigations of the marine atmosphere. We would like to express special thanks to World Trade Center Building (Osaka), Inc. for their support and for offering such a good monitoring platform. Finally, we acknowledge Dr. S. Hayakari of Aomori Prefecture Institute of Public Health and Environment for providing the software to describe wind vectors.

\section{REFERENCES}

Atkinson, R., D. L. Baulch, R. A. Cox, R, F. Jr. Hampson, J. A. Kerr, and J. Tore, 1989: Kinetic and photochemical data for atmospheric chemistry: Supplement III.J. Phys. Chem. Ref. Data, 18, 881-1097.

Baldasano, J. M., E. Valera, and P. Jiménez, 2003: Air quality data from large cities. Sci. Total Environ., 307, 141-165.

Bureau of Agriculture, Forestry and Fisheries of Osaka Prefecture, 2001: Osaka-fu Kankyo Hakusho (Environmental White Paper of Osaka Prefecture), Bureau of Agriculture, Forestry and Fisheries of Osaka Prefecture, Osaka City. (in Japanese)

Cooper, D. A., 2001: Exhaust emission from high speed ferries. Atmos. Environ., 35, 4189-4200.

Cooper, D. A., 2003: Exhaust emissions from ships at berth. Atmos. Environ., 37, 3817-3830.

Cooper, D. A., and K. Andreasson, 1999: Predictive NOx emission monitoring on board a passenger ferry. Atmos. Environ., 33, 4637-4650.

Corbett, J. J., 2002: Emission from ships in the northwestern United States. Environ. Sci. Technol., 36, 1299-1306.

Isakson, J., T. A. Persson, and E. Selin Lindgren, 2001: Identification and assessment of ship emissions and their effect in the harbor of Goteborg, Sweden. Atmos. Environ., 35, 3659-3666.

Osakawan Traffic Advisory Service Center, Japan Coast Guard, 2003: Osakawan Kaijo Kotsu Senta Tokei Shi, Osakawan Traffic Advisory Service Center, Japan Coast Guard, Awaji City, Japan. (in Japanese) 
Kley, D., M. Kleinmann, H. Sanderman, and S. Krupa, 1999: Photochemical oxidants: State of the science. Environ. Pollut., 100, 19-42.

Kondo, A., K. Yamaguchi, and E. Nishikawa, 1999: Influence of ship emissions on atmospheric pollutants concentrations around Osaka Bay area. Kansai Zosen Gakkaishi, 231, 101-109. (in Japanese with English abstract)

Lee, S. D. Ed., 1980: Nitrogen Oxides and Their Effects on Health, Ann Arbor Sciences, Ann Arbor.

Nishikawa, E., T. Matsumoto, and K. Okita, 1997: Measurements of atmospheric concentration of NOx and $\mathrm{SO}_{2}$ in the sea areas of Osaka Bay and Seto inlands Sea. Bull. MESJ, 25, 69-76.

Nishikawa, E., and M. Nagano, 1998: Synthetic analysis of air pollution over the land- and sea regions of Osaka Bay area, Proc. Techno-Ocean'98 Internat. Symp., Japan Inter. Mar. Sci. Technol. Fed., Tokyo, 93-97. (in Japanese with English abstract)

Ohara, T., S. Wakamatsu, and I. Uno, 2001: Numerical simulation of springtime air pollution in Kansai region: (2) Analysis of air pollution formation. J. Jpn. Soc. Atom. Environ., 36, 231-243. (in Japanese with English abstract)

Saxe, J., and T. Larsen, 2004: Air pollution from ships in three Danish ports. Atmos. Environ., 38, 4057-4067.

Seinfeld, J. H., 1975: Air pollution: Physical and chemical fundamentals, McGraw-Hill, Inc., New York, 1975.

Shi, J. P., and R. M. Harrison, 1997: Regression modeling of hourly NOx and $\mathrm{NO}_{2}$ concentrations in urban air in London. Atmos. Environ., 31, 4081-4094. 